\title{
PENGARUH JENIS UMPAN TERHADAP HASIL TANGKAPAN IKAN PANCING LAYANG-LAYANG DI SELAT BANGKA KABUPATEN MINAHASA UTARA
}

\author{
Stevenly A. Takapaha"), Henry James Kumajas ${ }^{\star *}$, Elof Machten Katiandagho**) \\ $\left.{ }^{*}\right)$ Pengawas Perikanan Direktorat Jenderal P2SDKP, \\ ${ }^{* *}$ Staf Pengajar pada Program Studi Pemanfaatan Sumberdaya Perikanan, \\ Fakultas Perikanan dan IImu Kelautan. UNSRAT. Manado 95115.
}

\author{
ABSTRACT \\ Takapaha, S.A., H.J. Kumajas, E.M. Katiandagho, 2010. \\ Effect of bait types on fish catch with kite fishing In Bangka Strait North \\ Minahasa Regency. Jurnal Perikanan dan Kelautan. Vol VI (1): 22-30.
}

Hound needlefish (Cendro or Sako) (Tylosurus sp.) including the types of fish are hard to catch because the surface movements and jumps very agile, is an effective fishing gear to catch this fish is to use a kite fishing.

This study aimed to see whether there is the influence of several kinds of bait such as: blue sprat (Spratelloides robustus), sardines (Amblygaster sirm), fish cutlet mackerel scad (Decapterus macarellus), and anchovy (Stolephorus indicus) of the catch.

The method used is descriptive. Data was collected by use four units of fishing kites gear with four types of bait treatment. Based on the analysis we found that the type of bait blue sprat better than mackerel scad and anchovy bait but not significantly different from the bait sardines, which are types of fish caught is Strongylura indicus (4\%), Tylosurus Crocodiles (90\%) and Tylosurus acus melanotus (6\%).

Keywords: Kite fishing, hound needlefish, bait type, Bangka Strait, North Minahasa.

\section{PENDAHULUAN}

Pola pemanfaatan sumberdaya ikan yang diinginkan adalah berkelanjutan dan bertanggung jawab. Sumberdaya perikanan dan kelautan merupakan elemen yang essensial bagi hamper $60 \%$ penduduk Indonesia yang umumnya tinggal di pesisir, dimana $80 \%$ dari penduduk wilayah pesisir bekerja di sektor perikanan.

Ikan cendro (Tylosurus sp.), di Sulawesi Utara dikenal dengan nama ikan sako yang merupakan salah satu sumberdaya perikanan ekonomis penting. Potensi ikan cendro diduga cukup besar, namun hingga saat ini belum ada laporan ilmiah yang menyebutkan jumlah pastinya.

Reppy (1993), menyatakan bahwa ikan cendro termasuk ikan permukaan yang sulit tertangkap karena pergerakkan sangat gesit, jarang tertangkap dengan jaring, umumnya tertangkap dengan pancing layang-layang.

Dalam perikanan pancing, sifat ikan yang dimanfaatkan adalah rangsangan yang timbul baik dari dalam ataupun dari luar. Dari dalam adalah rangsangan terhadap makanan, sedangkan dari luar adalah tertarik pada warna, bau, bentuk dan gerakan dari umpan yang digunakan. Menurut Gunarso (1985), mengemukakan bahwa umpan yang digerak-gerakan secara terus menerus dapat mempengaruhi penglihatan ikan dalam air. Hal ini didukung oleh Protosov (1970), bahwa setiap Ikan mempunyai keinginan dan terangsang terhadap warna, bau dan bentuk makanan yang ada di perairan.

Berdasarkan pemikiran dan pengembangan perikanan pancing maka dilakukanlah penelitian mengenai pengaruh jenis umpan terhadap hasil tangkapan ikan dengan pancing layang-layang di Selat Bangka Kabupaten Minahasa Utara. 
Secara umum penelitian ini bertujuan untuk mengembangkan teknologi pemanfaatan sumberdaya perikanan cendro,mempelajari pengaruh jenis umpan terhadap hasil tangkapan, mengidentifikasi jenis-jenis ikan cendro yang tertangkap dengan pancing layang-layang serta diharapkan akan dapat memberikan informasi ilmiah juga sebagai bahan pertimbangan dalam menentukan kebijakan pengembangan teknologi pemanfaatan sumberdaya perikanan cendro yang ramah lingkungan di Sulawesi Utara.

\section{METODE PENELITIAN}

Penelitian ini didasarkan pada metode deskriptif, yaitu suatu metode dalam menyelidiki suatu obyek atau klas peristiwa pada masa sekarang (Nazir, 1999), tujuannya adalah untuk membuat deskripsi atau gambaran secara sistimatis faktuan dan akurat mengenai fakta-fakta dan sifat serta hubungan antar fenomena yang diselidiki.

\section{Teknik Pengumpulan Data}

Pengumpulan data dilakukan dengan pengamatan langsung dan tidak langsung. Pengamatan langsung merupakan data primer yaitu pengamatan selama operasi penangkapan ikan dengan pancing layang-layang, sedang data sekunder melalui studi pustaka.

Data primer didapatkan dengan cara pengoperasian 4 unit pancing layanglayang dan empat jenis umpan yang digunakan sebagai perlakuan adalah: ikan Tandipang (Sardinella gibosa), sardine (Amblygaster sirm), sayatan malalugis (Decapterus macarellus) dan ikan teri (Stolephorus indicus) seperti pada Tabel 1.

Penempatan setiap perlakuan ditempatkan secara acak pada 4 unit perahu pancing, hal ini untuk menghindari pilih kasih terhadap perlakuan yang akan dicobakan sehingga setiap perlakuan yang dibuat mempunyai peluang yang sama untuk termakan oleh ikan.

Hasil tangkapan dikumpulkan tiap jam oleh sebuah perahu pengumpul, selanjutnya diukur, ditimbang dan dicatat pada table pengamatan yang telah disediakan.

Tabel 1. Jenis umpan yang digunakan pada penelitian

\begin{tabular}{|c|c|}
\hline Perlakuan & Jenis umpan \\
\hline $\mathrm{A}$ & $\begin{array}{l}\text { ikan Tandipang } \\
\text { (Sardinella gibosa), }\end{array}$ \\
\hline B & $\begin{array}{l}\text { sardine } \\
\text { (Amblygaster sirm), }\end{array}$ \\
\hline $\mathrm{C}$ & $\begin{array}{l}\text { sayatan malalugis } \\
\text { (Decapterus macarellus) }\end{array}$ \\
\hline$D$ & $\begin{array}{l}\text { ikan teri } \\
\text { (Stolephorus indicus) }\end{array}$ \\
\hline
\end{tabular}

Asumsi-asumsi:

1. Ikan Cendro terdapat dan menyebar merata di lokasi penangkapan,

2. Nelayan mempunyai ketrampilan yang sama dalam menggunakan pancing layang-layang,

3. Kondisi oseanografis daerah penangkapan ikan dianggap homogen.

\section{Teknik Analisis Data}

Hasil tangkapan ikan cendro dianalisis dengan menggunakan model Rancangan Acak Kelompok (RAK), dengan rumus matematis sebagai berikut:

$$
\begin{aligned}
Y_{i j} & =\mu+\mu_{i}+\beta_{j}+E_{i j} \\
\text { Dinama } & i=1,2,3, \ldots . t \\
& j=1,2,3, \ldots . r
\end{aligned}
$$

Tabel 2. Daftar Analisis Sidik Ragam

\begin{tabular}{l|c|c|c|c}
\hline $\begin{array}{c}\text { Sumber } \\
\text { keragaman }\end{array}$ & $\mathbf{d b}$ & JK & KT & F \\
\hline Kelompok & $\mathrm{r}-1$ & $\mathrm{JKr}$ & $\mathrm{KTr}$ & $\mathrm{Fhr}$ \\
Perlakuan & $\mathrm{t}-1$ & $\mathrm{JKt}$ & KTt & Fht \\
Acak & $(\mathrm{r}-1)(\mathrm{t}-1)$ & JKE & KTE & \\
\hline Total koreksi & $(\mathrm{rt}-1)$ & $\mathrm{JKT}$ & & \\
Nilai tengah & 1 & FK & & \\
\hline Total & $\mathrm{rt}$ & JKT $+\mathrm{FK}$ & &
\end{tabular}


Perlakuan dalam penelitian ini adalah penggunaan 4 jenis umpan, yaitu ikan sardine, tandipang, sayatan malalugis dan ikan teri yang dioperasikan dalam 6 kelompok waktu, yaitu: jam pertama (09.00-10.00); kedua (10.01-11.00), ketiga (11.01-12.00); keempat (12.01-13.00); kelima (13.01-14.00); dan keenam (14.0115.00). Jika penggunaan perlakuan berpengaruh, maka dilanjutkan dengan uji Beda Nyata Terkecil (BNT) (Steel and Torrie, 1989), untuk mengetahui seberapa besar perbedaannya digunakan rumus:

$$
\operatorname{BNT}(0,01)=\mathrm{t}(\mathrm{db} \text { acak, } 0,01) \times \mathrm{Sd} \text {, dimana } \mathrm{Sd}=\sqrt{\frac{2 K T E}{n}}
$$

dimana $\mathrm{BNT}_{(0,01)}=$ Beda nyata terkecil pada tingkat kepercayaan $99 \%$

$\mathrm{t}_{(\mathrm{db} \text { acak, 0,01) }}=$ Simpangan baku beda nilai tengah

KTE $=$ Kuadrat tengah acak

$\mathrm{Sd}=$ Simpangan baku nilai tengah

$n=$ ulangan

\section{METODE PENANGKAPAN IKAN}

\section{Deskripsi alat tangkap ikan}

\section{Penggulung dan tali ulur}

Penggulung (Gambar 1) yang digunakan terbuat dari bahan kayu berbentuk persegi panjang dengan panjang $30 \mathrm{~cm}$ dan lebar $20 \mathrm{~cm}$.

\section{Joran/Tangkai}

Joran/tangkai, berfungsi sebagai media tempat dilaluinya tali ulur yang terbuat dari bambu. Tali ulur yang digunakan adalah PA monofilamen No 300 . Joran yang digunakan pada alat tangkap ini terbuat dari bambu dengan panjang 4 meter dan diameter $5 \mathrm{~cm}$ pada bagian pangkal.

\section{Layang-layang}

Penangkapan ikan dengan menggunakan layang-layang (kite fishing) (gambar 3) merupakan cara penangkapan yang unik. Layangan yang digunakan dari sehelai daun tébang kering (Osmunda sp) yang berfungsi untuk mengangkat umpan agar tetap berada di atas permukaan air.

\section{Tali jerat}

Tali jerat berfungsi agar ikan yang memakan umpan terjerat rahang atasnya dan sulit terlepas. Tali jerat dibentuk melingkar

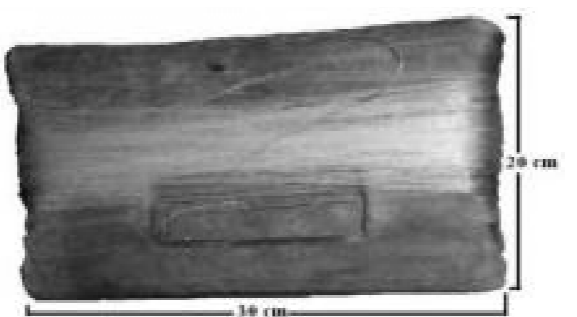

Gambar 1. Penggulung dan tali ulur

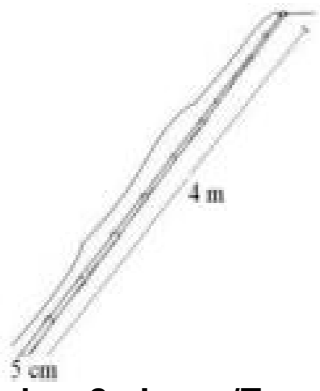

Gambar 2. Joran/Tangkai

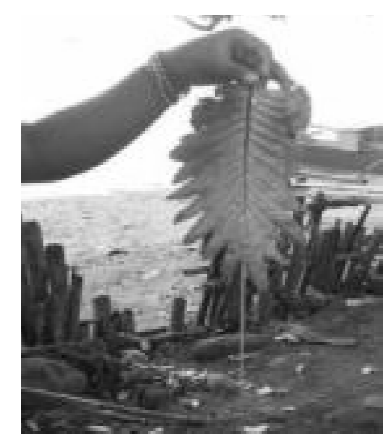

Gambar 3. Layang-layang menggunakan simpul laso, dengan panjang sekitar $30 \mathrm{~cm}$ tergantung ukuran umpan.

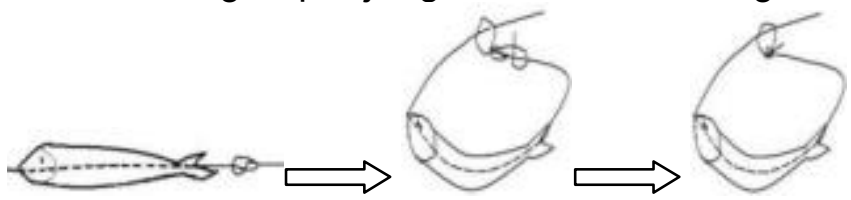

Gambar 4. Tali jerat 
Tabel 3. Spesifikasi pancing layang-layang

\begin{tabular}{clcccc}
\hline Tanda & Nama bagian & Material & Lebar $(\mathbf{m})$ & Panjang $(\mathbf{m})$ & Jumlah \\
\hline 1. & Penggulung & Kayu & 0,20 & 0,30 & 4 \\
2. & Tangkai (Joran) & Bambu & - & 4 & 4 \\
3. & Tali ulur & PA Mono No.300 & - & $20-50$ & 4 \\
4. & Layang-layang & Daun & - & 0,40 & 4 \\
5. & Lidi daun kelapa & & & 0,30 & 4 \\
6. & Tali jerat & PA Mono No.300 & - & 0,30 & 4 \\
\hline
\end{tabular}

\section{Spesifikasi perahu penangkapan}

Alat bantu penangkapan berupa perahu tipe pelang yang digunakan memiliki karakteristik sebagai berikut:

Tabel 4. Spesifikasi Perahu Penangkapan

\begin{tabular}{clccc}
\hline Perahu & \multicolumn{1}{c}{ Jenis Umpan } & $\begin{array}{c}\text { Panjang } \\
(\mathbf{m})\end{array}$ & $\begin{array}{c}\text { Lebar } \\
(\mathbf{m})\end{array}$ & $\begin{array}{c}\text { Dalam } \\
(\mathbf{m})\end{array}$ \\
\hline Perahu I & ikan Tandipang (Sardinella gibosa), & 5,30 & 0,36 & 0,49 \\
Perahu II & ikan sardine (Amblygaster sirm), & 6,0 & 0,47 & 0,56 \\
Perahu III & sayatan malalugis (Decapterus macarellus) & 5,0 & 0,43 & 0,56 \\
Perahu IV & ikan teri (Stolephorus indicus) & 4,90 & 0,40 & 0,54 \\
\hline
\end{tabular}

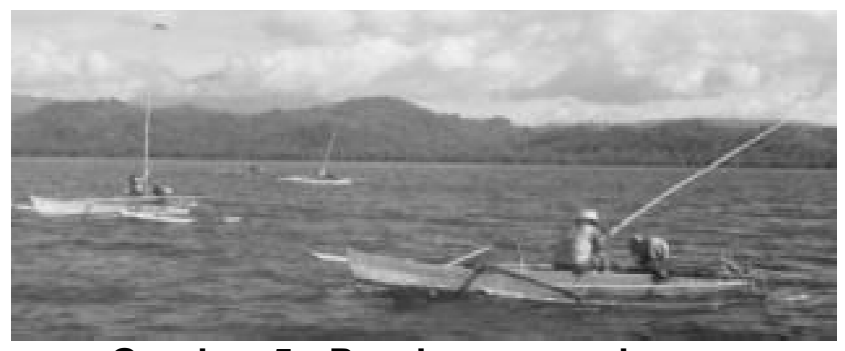

Gambar 5. Perahu penangkapan

\section{Operasi penangkapan ikan}

\section{Kesiapan alat tangkap ikan}

Kegiatan yang dilakukan sebelum berangkat ke daerah operasi adalah mempersiapkan segala sesuatunya yang berhubungan dengan operasi penangkapan yaitu dimulai dari menyiapkan daun tébang (Osmunda sp) yang akan digunakan sebagai layang-layang. Daun yang dipilih biasanya yang berukuran lebar, kering dan tidak memiliki sobekan. Persiapan yang lain adalah menyiapkan umpan ikan tandipang dan sardin yang diperoleh dari bagan juga ikan teri dan sayatan malalugis.

\section{Daerah penangkapan ikan}

Daerah penangkapan pancing layang-layang adalah perairan berarus, di daerah karang yang dangkal dekat dengan daerah tepi pantai. Pada penelitian ini daerah penangkapan ikan sako adalah di napo panjang Selat Bangka dengan posisi $01^{\circ} 41^{\prime} 31,7$ "LU, $125^{\circ} 02^{\prime} 48,0^{\prime \prime}$ BT dan $01^{\circ} 41^{\prime} 26,0^{\prime \prime}$ LU, $125^{\circ} 02^{\prime} 09,7^{\prime \prime}$ BT.

\section{Pengoperasian pancing layang-layang}

Pengoperasian alat tangkap pancing layang-layang dilakukan pada pagi hingga sore hari ketika angin bertiup. Faktor angin dalam penangkapan sangat berpengaruh, setelah angin yang bertiup dianggap dapat menerbangkan layangpun dilepas pada jarak tertentu kira-kira 20-50 meter dari perahu. Disini nelayan menunggu Ikan yang memakan umpan akan terjerat pada bagian rahang atas dengan simpul laso dan akhirnya dapat ditangkap dan dinaikan ke perahu, kemudian pengoperasianpun dapat dilanjutkan. Dalam penelitian ini empat alat tangkap pancing layang-layang dioperasikan pada masing-masing perahu dimana keempat 
alat tangkap pancing layang-layang yang berbeda umpan dioperasikan secara bersama-bersama. Selang waktu satu jam peneliti menghitung dan mencatat jumlah hasil tangkapan dari masing-masing alat tangkap.

\section{HASIL DAN PEMBAHASAN}

\section{Hasil Tangkapan}

Hasil tangkapan selama penelitian berjumlah 67 ekor, terdiri dari 28 ekor perolehan umpan tandipang (Sardinella gibosa), 20 ekor perolehan umpan sardin (Amblygaster sirm), 11 ekor perolehan umpan sayatan malalugis (Decapterus macarellus) dan 8 ekor perolehan umpan teri (Stolephorus inducus). Jumlah hasil tangkapan pancing layang-layang ini dapat dilihat pada Tabel 5.

Tabel 4. Hasil tangkapan ikan

\begin{tabular}{|c|c|c|c|c|c|}
\hline \multirow{2}{*}{$\begin{array}{l}\text { WAKTU } \\
\text { OPERASI }\end{array}$} & \multicolumn{4}{|c|}{ JENIS UMPAN } & \multirow{2}{*}{ TOTAL } \\
\hline & Tandipang & Sardin & Sayatan malalugis & Ikan Teri & \\
\hline $09.00-10.00$ & 3 & 2 & 1 & 1 & 7 \\
\hline $10.01-11.00$ & 6 & 4 & 2 & 1 & 13 \\
\hline $11.01-12.00$ & 5 & 3 & 2 & 2 & 12 \\
\hline $12.01-13.00$ & 3 & 4 & 2 & 1 & 10 \\
\hline $13.01-14.00$ & 4 & 3 & 2 & 2 & 11 \\
\hline $14.01-15.00$ & 7 & 4 & 2 & 1 & 14 \\
\hline Total & 28 & 20 & 11 & 8 & 67 \\
\hline Rataan & 4,67 & 3,33 & 1,83 & 1,33 & 2,79 \\
\hline
\end{tabular}
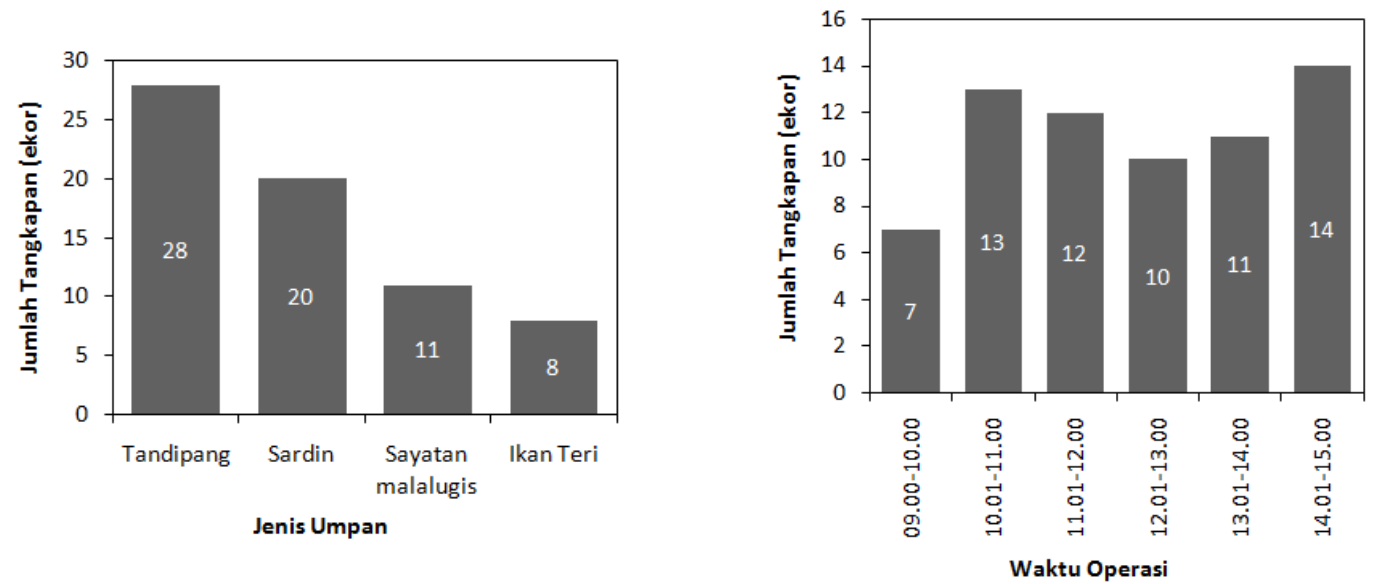

Gambar 6. Grafik jumlah hasil tangkapan Gambar 7. Grafik jumlah hasil tangkapan berdasarkan jenis umpan berdasarkan waktu operasi

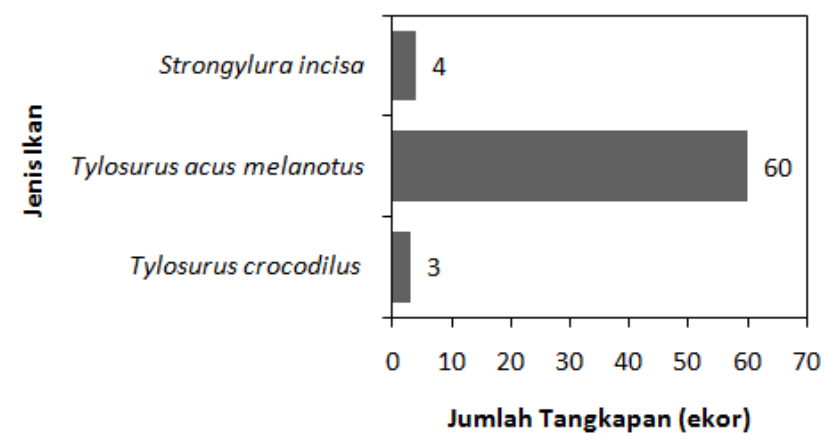

Gambar 8. Grafik jumlah hasil tangkapan berdasarkan jenis ikan 
Berdasarkan Gambar 6 hingga Gambar 8 dapat dilihat bahwa ikan cendro di perairan Selat Bangka pada umumnya lebih menyukai umpan jenis tandipang, kemudian ikan sardin, ikan sayatan malalugis dan yang terakhir ikan teri. Sedang jenis ikan yang dominan tertangkap adalah Tylosurus crocodilus kemudian Tylosurus acus melanotus dan Strongylura incise.

\section{Hasil Analisa Data}

Untuk melihat pengaruh setiap perlakuan pada jenis umpan maka dilakukan analisis keragaman Rancangan Acak Kelompok (RAK). sebagai berikut :

Dari hasil analisa

sidik ragam diketahui bahwa berapa jenis umpan berpengaruh sangat nyata terhadap hasil tangkapan, dengan demikian Hipotesis $\mathrm{H}_{0}: \pi=0$, ditolak, sedangkan hipetesis alaternatif $\quad \mathrm{H}_{1}: \pi \neq 0$ Tabel 5. Hasil analisa sidik ragam

\begin{tabular}{|c|c|c|c|c|c|c|}
\hline Sumber & $d h$ & IK & KT & $F_{-}$ & & \\
\hline & 0 & $J_{n}$ & $\mathbf{R} 1$ & $r_{\text {hit }}$ & 0.05 & 0.01 \\
\hline Perlakuan & 3 & 41.125 & 13.708 & 18.483 & 3.29 & 5.42 \\
\hline Kelompok & 5 & 7.708 & 1.542 & ns 2.0787 & 2.90 & 4.56 \\
\hline Galat & 15 & 11.125 & 0.742 & & & \\
\hline N. Tengah & 1 & 187.040 & & & & \\
\hline Total & 24 & 59.960 & & & & \\
\hline Keterangan & $\begin{array}{l}* * \\
\mathrm{~ns}=\end{array}$ & & & $\begin{array}{l}\text { ta } \\
\text { k ber }\end{array}$ & $a$ & \\
\hline
\end{tabular}
diterima. Untuk mengetahui jenis umpan mana yang paling berpengaruh terhadap hasil tangkapan baik untuk jenis umpan ikan tandipang (A), ikan sardin (B), ikan layang (C) maupun ikan Putih (D), maka dilanjutkan dengan uji Beda Nyata Terkecil (BNT) yang hasilnya sebagai berikut :

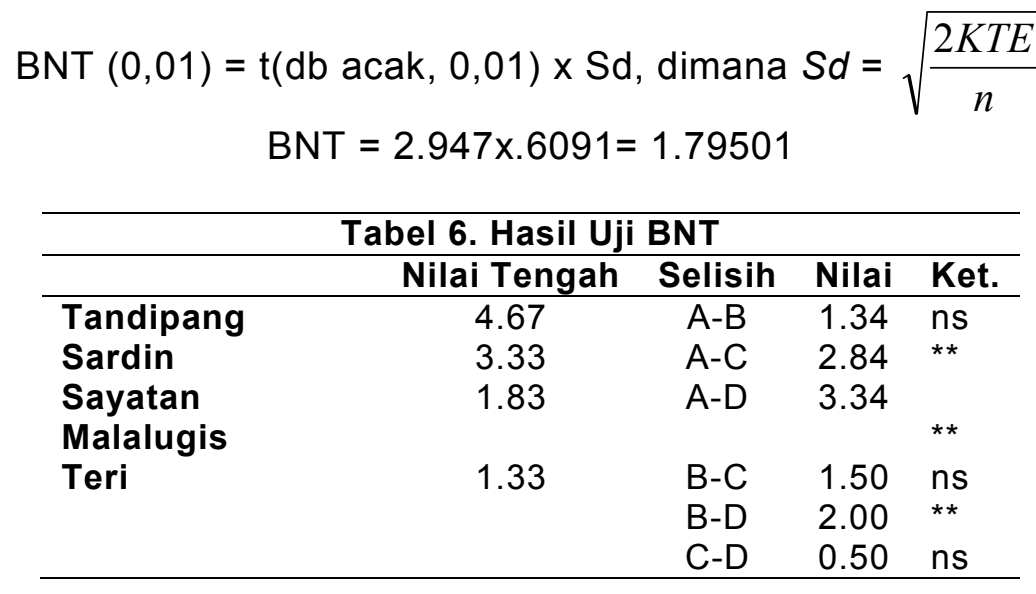

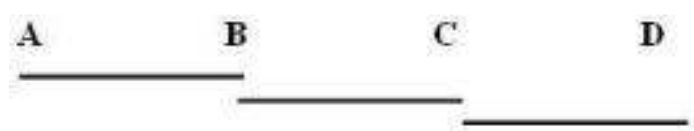

Dari hasil uji BNT didapatkan bahwa jenis umpan A (tandipang) berbeda sangat nyata dengan umpan $\mathrm{C}$ (sayatan malalugis), dan $\mathrm{D}$ (teri) tetapi tidak berbeda nyata dengan umpan B (sardin), Jenis umpan B (sardin) tidak berbeda nyata dengan umpan $\mathrm{D}$ (teri), tetapi berbeda sangat nyata dengan $\mathrm{C}$ (sayatan malalugis), dan jenis umpan $\mathrm{C}$ (sayatan malalugis) tidak berbeda nyata dengan umpan $\mathrm{D}$ (teri).

\section{Pembahasan}

Berdasarkan Gambar 10, terlihat bahwa jenis umpan yang dominan termakan ikan cendro adalah umpan tandipang, diikuti umpan sardin, sayatan malalugis dan yang paling sedikit umpan teri, hal ini dikarenakan umpan tandipang memiliki warna tubuh yang lebih mengkilat dibandingkan dengan umpan-umpan yang lain serta bentuk tubuh yang lebih lebar. Tingkah laku ikan cendro yang senang mencari 
makan dengan menggunakan indera penglihatan menyebabkan umpan-umpan yang menarik dengan warna dan bentuk tertentu lebih disukai.

Dari Tabel 5 dapatlah dilihat $F_{\text {tabel }}>F_{\text {hitung }}$ yang secara statistika artinya waktu operasi tidak berbeda nyata atau tidak berpengaruh terhadap jumlah hasil tangkapan, walaupun pada Gambar 7 terlihat pada histogram ada perbedaan jumlah hasil tangkapan, namun hal ini bukanlah pengaruh waktu tetapi faktor yang lain seperti tiupan angin, dimana jam-jam tertentu kecepatan angin sangat cocok untuk mengkondisikan umpan berada di atas permukaan air laut dan pada jam-jam yang lain kecepataan angin kurang memadai; Ketika angin bertiup terlalu kuat, maka layangan sulit dikendalikan, karena kadang layangan terangkat tinggi atau menukik ke air; selain itu karena angin semakin kuat bertiup maka gelombang semakin membesar menyebabkan tali laso dengan umpan yang bergerak tidak menentu pada puncak-puncak gelombang, yang mungkin membuat ikan cendro takut dan menghindar darinya. Faktor lain yang mempengaruhi adalah pasang surut air laut dimana pada jam-jam tertentu nelayan berpindah tempat ke daerah pinggiran terumbu karang yang berbatu untuk mendapatkan daerah penangkapan yang baik.

Dari hasil uji BNT umpan tandipang tidak berbeda nyata dengan umpan sardin namun berbeda nyata dengan umpan sayatan malalugis dan umpan teri, hal ini karena morfologi ikan tandipang mirip dengan ikan sardin 3, sedangkan umpan sardin tidak berbeda dengan ikan teri. Untuk umpan sayatan malalugis tidak berbeda nyata dengan umpan teri karena kedua umpan ini secara strukur kurang tahan di air sehingga mudah lepas dari tali jerat.

Secara umum dapatlah digambarkan bahwa tingginya hasil tangkapan pada umpan tandipang dan sardin selain warnanya yang keperak-perakan menonjol, juga ukurannya lebih lebar dan lebih menarik daripada umpan sayatan malalugis dan umpan teri. Ukuran umpan tandipang sekitar $9,5 \mathrm{~cm}$, sardin, $12 \mathrm{~cm}$, sayatan malalugis $9 \mathrm{~cm}$ dan ikan teri $7 \mathrm{~cm}$.

Untuk Gambar 8, dapat dilihat bahwa jumlah hasil tangkapan berdasarkan jenis ikan, 67 ekor (90\%) yang tertangkap adalah jenis Tylosurus crocodilus, 4 ekor (6\%) jenis Tylosurus acus melanotus dan 3 ekor (4\%) jenis Strongylura incisa

\section{KESIMPULAN DAN SARAN}

Kesimpulan
Berdasarkan hasil penelitian yang diperoleh dapat di tarik kesimpulan sebagai
berikut :

1. Penggunaan jenis umpan yang bebeda memberikan pengaruh yang sangat nyata terhadap hasil tangkapan ikan cendro dengan pancing layang-layang

2. Perlakuan jenis umpan tandipang tidak berbeda nyata dengan umpan sardin, tetapi berbeda sangat nyata denga umpan sayatan malalugis dan umpan teri; umpan sardin tidak berbeda nyata dengan sayatan malalugis tetapi berbeda sangat nyata dengan umpan teri; umpan malalugis tidak berbeda nyata dengan umpan teri

3. Hasil tangkapan ikan cendro di perairan Selat Bangka yang di kenal dengan nama ikan sako adalah jenis Strongylura incisa 3 ekor (4\%), Tylosurus crocodilus 60 ekor (90\%), dan Tylosurus acus melanotus 4 ekor (6\%)

\section{Saran}

1. Umpan yang baik adalah tandipang (Sardinella gibos) dan sardin (Amblygaster sirm) yang warnanya keperakan dan mudah menarik perhatian ikan.

2. Perlu penelitian lanjut di daerah penangkapan yang lain dengan umpan yang bervariasi, menggunakan alat tangkap pancing layang-layang. 


\section{DAFTAR PUSTAKA}

Allen, G. 2000. Marine fishes of South East Asia. Periplus. Singapore. 292 hal. Anonimous. 2005. Istilah defenisi alat tangkap pancing standar nasional Indonesia. Materi perubahan rancangan. Ditjen Perikanan tangkap. BPPI. Semaranng. 7 hal.

2007. Fishing/Tehnik-tehnik memancing ikan di laut. (http://wordpress.com/25 Mei 2007). 2008. Ikan cendro. (http://www. fishyforum.com).

Bonito. 2008. Taksonomi ikan cendro. (http://www.dogol22.multyply.com).

Dahuri. 2001. Info aktual industri perikanan tangkap Indonesia/ditjen perikanan tangkap. (http://www.dkp.go.id/03-03-05).

Efendie, M.I., 1978. Biologi Perikanan. Fakultas perikanan IPB. Bogor. 106 hal.

Gunarso, W.1985 Suatu pengantar tentang tingkah laku ikan terutama dalam hubungannya dengan alat, metode dan taktik penangkapan. Fakultas Perikanan IPB. Bogor. 142 hal. 1996. Tingkah laku ikan dan perikanan pancing. IPB. 151hal.

Katiandagho, E,H., Kumajas, H,J., dan Paturasi. 1991. Metode penangkapan ikan. Fakultas Perikanan Universitas Sam Ratulangi. 140 hal.

Lagler, J.F., J.E. Bardach and Miller. 1962. Ichthyology.the study of fishes. John Willey and Sons. London. $545 \mathrm{p}$.

Myers, P. 2008. The Animal Diversity Web (online). Accessed at http://animaldiversity.org.

Nasir, M. 1985. Metode Penelitian. Ghalia Indonesia. Jakarta. 597 hal.

Protosov. 1970. Visioin and Orientation of fish. Israel Program for Scinetific Translation. Jerusalem. 175 hal.

Raharjo, M,F.1980 Ichtyologi.Institut Pertanian Bogor.Fakultas Perikanan. Departemen Biologi Perairan, Bogor.125 hal

Reppy,R.R, 1993 Pengoperasian jaring Sollong diperairan pantai bebalang kecamatan Manganitu kabupaten kepulauan Sangihe Talaud.Laporan praktek ketrampilan lapang. Universitas Sam Ratulangi Fakultas Perikanan.Manado. (tidak dipublikasikan

Steel, R.G.D, and Torrie, J.H., 1989. Principles and Procedures of Statistics.Abiometrical Approach. 2 nd eEd. Mc Graw Hill International Book comapany. London. 633 p.

Syarfarudin Siregar., 2005. Statistika terapan untuk penelitian. PT. Grasindo, Jakarta 


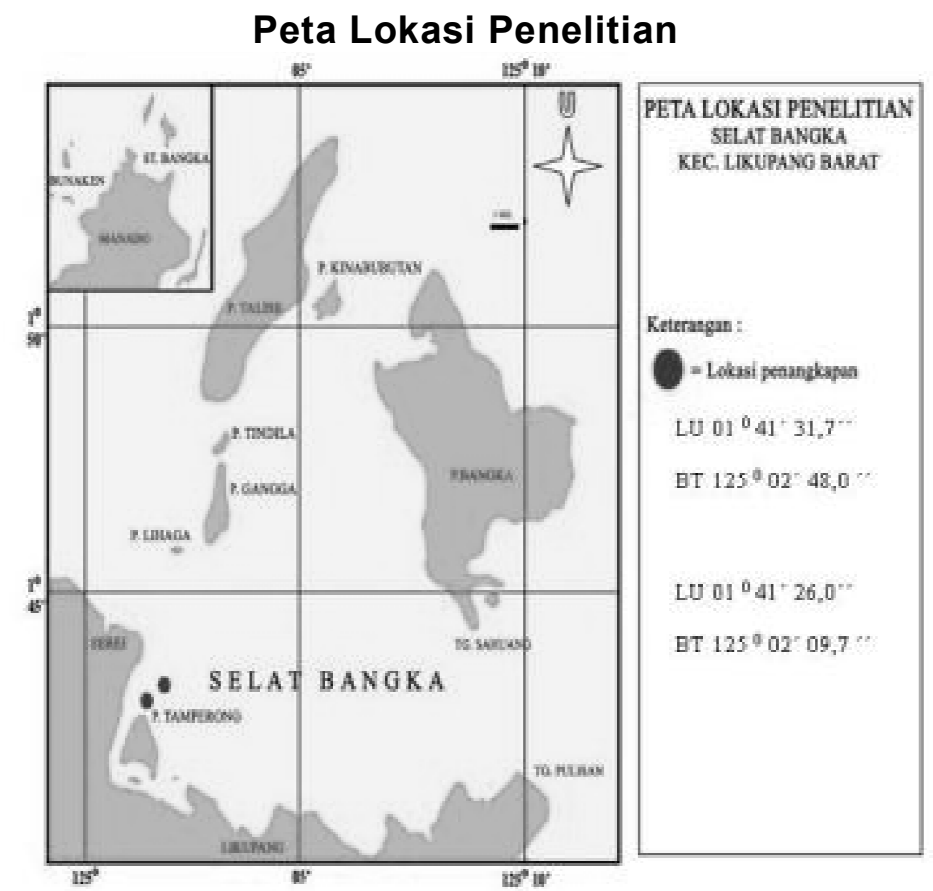

Sumber: Peta laut Indonesia TNI AL jawatan hidro oseanografi.1976

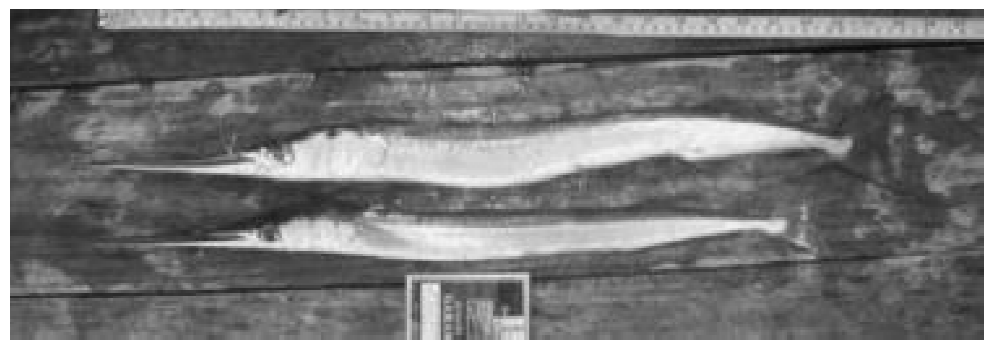

Ikan hasil tangkapan (Jenis Strongylura incisa)

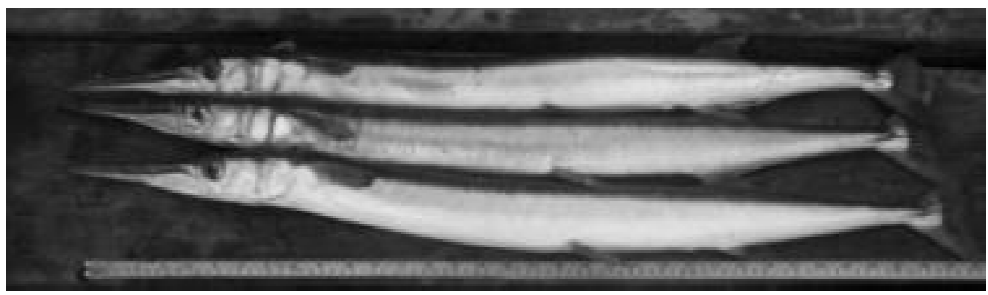

Ikan hasil tangkapan (Jenis Tylosurus crocodilus)

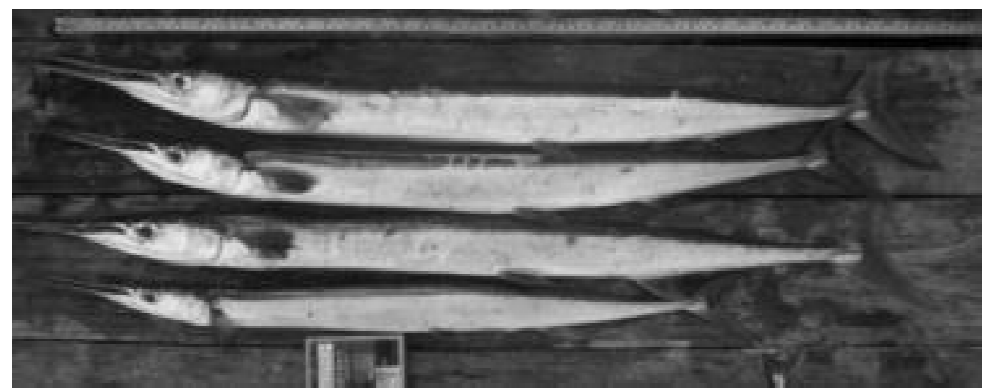

Ikan hasil tangkapan (Jenis Tylosurus acus melanotus) 